\title{
Functional Constipation in Children: Demography and risk factors analysis from a Tertiary Care Hospital of Bangladesh
}

\author{
MD. WAHIDUZZAMAN MAZUMDER ${ }^{1}$, SHARIFUL HASAN², KANIZ FATHEMA ${ }^{3}$, \\ MD. RUKUNUZZAMAN ${ }^{4}$, ASM BAZLUL KARIM $^{4}$
}

\begin{abstract}
Background: Constipation is not uncommon in childhood. This study was aimed to evaluate demography and probable/potential risk factors for functional constipation in Bangladeshi children.

Materials \& Method: This cross-sectional study was carried out among 179 children from May 2018 to June 2019 in the department of Pediatric Gastroenterology and Nutrition, BSMMU, Dhaka both indoor and outdoor basis. Collected data from children with constipation who fulfilled the Rome III criteria were analyzed by SPSS 20.

Results: Among 179 children, $54.75 \%$ were boys, and $45.25 \%$ girls. It was found more in age group above 5 years (56.42\%), then in 2 to 5 years (33.52\%) and lower in below 2 years (10.6\%). Constipation was more in urban areas (55.3\%) than in rural (44.69\%). Among potential risk factors, low fiber in diet (72.63\%) was most common, other factors were ingestion of cow's milk (32.96\%), not having regular meals with parents (19.55\%), consumption of junk foods (28.49\%), Staying with grandparents (16.76\%), living in hostel or madrasa / residential, religious institute (5.03\%), long period of academic activity (7.26\%), unhygienic toilet in school (6.14\%) were also found to be probable risk factors in this study.

Conclusion: Functional constipation was found more in boys \& above five-year age groups. Low dietary fiber, consumption of cow's milk \& junk food, unwillingness to use toilets in school were found as potential underlying risk factors of constipation.
\end{abstract}

Keywords: Constipation, Children, Probable risk factors.

\section{Introduction}

Constipation is one of the commonest problems in children. It has been problematic from ancient times to present, and it is seen world-wide in all races and cultures. ${ }^{1}$ Constipation is a symptom, not a disease.

1. Associate Professor, Department of Paediatric Gastroenterology \& Nutrition, Bangabandhu Sheikh Mujib Medical University (BSMMU), Bangladesh.

2. Medical officer, Department of Paediatric Gastroenterology \& Nutrition, BSMMU.

3. Resident, Phase-B, Department of Paediatric Gastroenterology \& Nutrition, BSMMU.

4. Professor, Department of Paediatric Gastroenterology \& Nutrition, BSMMU.

Correspondence: Dr. Md. Wahiduzzaman Mazumder, Department of Paediatric Gastroenterology \& Nutrition, Room no 511, Block D, Bangabandhu Sheikh Mujib Medical University (BSMMU), Cell no.-01718601459, email: mazumdermw@ gmail.com.

Received: 15/01/2020

Accepted: $17 / 12 / 2020$
Some patients regard constipation as straining (52\%), while for others, it means hard, pellet-like stool (44\%) or an inability to defecate when desired (34\%), or infrequent defecation (33\%). ${ }^{2}$ Functional constipation describes persistently difficult, infrequent, or seemingly incomplete defecation without evidence of a primary cause (anatomic, metabolic, or neurologic etc), this definition is operationalized by the "Rome III" diagnostic criteria, ${ }^{3}$ which requires at least two of six symptoms describing stool frequency, hardness, large size, fecal incontinence, or volitional stool retention for at least two month. Constipation is an important problem which leads to a high number of medical visits and also generates healthcare costs as a result of associated medical problems. ${ }^{4,5}$ The early and accurate assessment and prompt treatment of constipation is vital to the child's wellbeing and 
lifestyle. Delay in management will exacerbate the problem and perpetuate the child's lack of selfesteem. It is, therefore important to be fully aware of the factors involved in developing constipation in children. In this study, our aim was to evaluate demographic characters and potential underlying risk factors for functional constipation in Bangladeshi children.

\section{Materials and Methods}

This cross-sectional study was carried out among 179 children from May 2018 to June 2019 in the department of Pediatric Gastroenterology and Nutrition of Bangabandhu Sheikh Mujib Medical University (BSMMU) both in indoor and outdoor basis. All the children aged 12 months to 16 years attending indoor and outdoor who fulfilled the Rome III criteria for functional constipation were included in the study. Children already on the treatment of constipation, children with an organic cause of constipation, parents unwilling to attend the study were excluded from study. A structured questionnaire was used to collect data regarding demographic characteristics and probable underlying risk factors of constipation. Data regarding constipation parameters, physical or psychological disorders, personal (school phobia/temper tantrum) and family stressors (parental disharmony, sibling rivalry, death of family members) and the food habits of the child were also collected. Initially, 215 patients were enrolled in the study though 36 were excluded due to incomplete data. Finally, collected data of 179 children were analyzed. Rome III criteria established in 2006 was used to determine whether a child could be considered for functional constipation ${ }^{6,7}$ in which diagnostic criteria of functional constipation must include two or more of the following in a child with a developmental age of at least 4 years with insufficient criteria for diagnosis of functional constipation : two or fewer defecations in the toilet per week, at least one episode of fecal incontinence per week, history of retentive posturing or excessive volitional stool retention, history of painful or hard bowel movements, presence of a large fecal mass in the rectum, history of large diameter stools which may obstruct the toilet. Categorical data were expressed as absolute counts and percentages. Ethical approval was taken from the departmental ethical committee.

\section{Results}

A total of 179 subjects were included in the final analysis. Among them, $54.75 \%$ were boys and $45.25 \%$ girls. Constipation was found to be higher in more than 5 years of age group $56.42 \%$, and lower in bellow 2 years of age group $10.6 \%$. Among them $55.31 \%$ were living in urban where as $44.69 \%$ in rural (table-I). Constipation was the presenting complaint in $76.54 \%$ subjects, other complaints were abdominal pain $47.49 \%$, anorexia $24.02 \%$, vomiting $19.56 \%$ (tableII). Table-III reports potential underlying risk factors in the subjects with functional constipation. Dietary habits found to be one of the major probable risk factors among the subjects. Low fiber diet was found in $72.63 \%$ children with constipation, among other probable causes, ingestion of cow's milk $32.96 \%$, not having regular meals with parents $19.55 \%$, consumption of junk foods was found in $28.49 \%$ cases. Psychological factors play an important role too. Staying with grandparents $16.76 \%$, psychological stress $2.79 \%$, living in hostel or madrasa/religious residential institute $5.03 \%$ found to be potential associated factors in this study (table-III). Less physical activity found in $7.23 \%$ and child obesity in $2.23 \%$ subjects. Among academic factors, a long period of homework was found in $10.61 \%$, busy with tutor and coaching in $7.26 \%$, unhygienic toilet of school in $6.14 \%$ cases of children with constipation. We found constipation $6.7 \%$ in the low income group, and $3.35 \%$ where the mother was a service holder.

Table-I

Demographic characteristics of study subjects $(n=179)$

\begin{tabular}{lc}
\hline Demographic characteristics & Number (\%) \\
\hline Gender & \\
$\quad$ Male & $98(54.75)$ \\
$\quad$ Female & $81(45.25)$ \\
Age groups (years) & \\
$<2$ & $18(10.06)$ \\
$2-5$ & $60(33.52)$ \\
$>5$ & $101(56.42)$ \\
Living area & \\
Urban & $99(55.31)$ \\
Rural & $80(44.69)$ \\
\hline
\end{tabular}


Table-II

Presenting complaints of study subjects ( $n=179)$

\begin{tabular}{lc}
\hline Presenting complaints & Number $(\%)$ \\
\hline Constipation & $137(76.54)$ \\
Abdominal pain & $85(47.49)$ \\
Anorexia & $43(24.02)$ \\
Vomiting & $35(19.56)$ \\
\hline
\end{tabular}

Table-III

Probable associated factors related to constipation in study subjects $(n=179)$

\begin{tabular}{lc}
\hline Probable risk factors & Number (\%) \\
\hline Dietary factors & $130(72.63)$ \\
Diet low in fibers & $59(32.96)$ \\
Cow's milk intake & $35(19.55)$ \\
Not having regular meals with parents & $51(28.49)$ \\
Consumption of junk food & \\
Psychological factors & $5(2.79)$ \\
Psychological stress & $30(16.76)$ \\
Stays with grandparents & $9(5.03)$ \\
Lives in hostel or madrasa & $3(1.68)$ \\
Maidservant care giver & $13(7.26)$ \\
Less physical activity & \\
(no exercise/sports) & $7(2.23)$ \\
Obese child & \\
Academic activity related & $19(10.60)$ \\
Long periods for homework & $13(7.26)$ \\
Busy with tutors/coaching class & $11(6.14)$ \\
Unhygienic toilet in school & \\
Social condition & $12(6.70)$ \\
Low-income family & $6(3.53)$ \\
Working / service holder mother & \\
\hline
\end{tabular}

\section{Discussion}

In this study, we evaluated 179 children with constipation and found slight male preponderance (54.75\%). Chan et al. ${ }^{8}$ and Kajiwara et al. ${ }^{9}$ found an increased prevalence in girls, though Gannikou $R$ et al. ${ }^{10}$ and Khanna et al. ${ }^{11}$ also found a male preponderance, which is similar to our study. We found constipation more common in the above five years age group (56.42\%) and Kondapalli et al found, 57\% of children had constipation in 2-4 years age group in their study. ${ }^{2}$ This difference may be due to the changing pattern of toilet training, attention differences of caregivers, and the difference in regional food habits.

Constipation seems to be a more prevalent problem in families with lower education and low-income communities like slum and rural areas. ${ }^{12,13}$ The difference may result from diet habits (high rice/ carbohydrate), environmental, cultural, and racial reasons and may also be caused by different study methods. Our study result shows $55.31 \%$ of children with constipation were living in urban, whereas $44.69 \%$ in rural areas.

Kondapalli et al. ${ }^{2}$ in their study observed, $30.6 \%$ of children with constipation presented with recurrent abdominal pain, while in our study, we found $47.49 \%$ of children presented with recurrent abdominal pain, which is closer to that study. The causes of abdominal pain may be due to fecal and gaseous loading of the gut. Constipation may also present with anorexia, vomiting. ${ }^{14}$ We found anorexia in $24 \%$, vomiting in $19.6 \%$ as the presenting complaint in this study.

Low dietary fiber, has often been considered as an important determinant of constipation. ${ }^{15}$ Dietary fiber is known to have an extra beneficial effect on constipation due to its fecal bolus-mass incrementing effect, water retention properties, increasing colon bacteria, and gas production, with an acceleration of colon transit. ${ }^{5}$ In our study, we found, constipated children had a lower consumption rate of vegetables and fruits $72.63 \%$ and a higher consumption of junk foods (fried \& baked items) $28.49 \%$, which contains low fiber, results are similar to the previous studies. ${ }^{16-18}$ Andiran et al. ${ }^{19}$ suggested that increased consumption of cow's milk was found to be a risk factor for childhood constipation. According to these authors, constipation may be secondary results of cow's milk intolerance or cow's milk protein allergy. However, cow's milk might cause constipation by other mechanisms like allergic colitis with inflammatory infiltrates in the lamina-propria or calcium fatty acid soap formation in sticky feces. ${ }^{9}$ We also found that the consumption of cow's milk was in $32.96 \%$ constipated children, which is nearly similar to the Andiran et al. ${ }^{19}$ where they have found it in $30 \%$ of cases.

Some studies have shown that increased levels of psychological stress are associated with constipation. ${ }^{20}$ It was also suggested that family events might be a causative factor for constipation in 
children. Ozokutan et al. ${ }^{20}$ showed $88 \%$ of children with constipation followed a stressful event in their families (birth, death, parents' separation and, immigration). In our study, $16.76 \%(n=30)$ of children with constipation were staying with grandparents, and $5.03 \%$ of children residing in the hostel or madrasa/ religious residential school and $2.7 \%$ had other psychological stressors like personal (school phobia/ temper tantrum) and familial issues. (parental disharmony, sibling rivalry, death of family members).

In this study, we found that $6.14 \%$ of children refused to defecate at school. This may because, as well as a consequence of constipation. Cause of refusal may be the issue of the poor toilet environment, and this is impacting more on the constipated child. According to a study performed by Lundblad et al. ${ }^{21}$ many children influenced by negative perceptions of school toilets have adopted unhealthy toilet habits during school time. Their negative perceptions of school toilets develop on the physical appearance of the toilets and on feelings of insecurity when visiting the toilet. For most of the children, a toilet visit away from home can create a psychological strain. Vernon et al. ${ }^{22}$ also reported that the avoidance of school toilets has negative consequences for children, such as a higher risk of developing constipation, incontinence, and/or urinary tract infection. Our findings are parallel to these ideas.

In the current study, we also found parent's anxiety/ complaints about academic factors like a long time for homework (10.6\%), for tutors/coaching $(7.26 \%)$ that poses a negative impact on regular bowel movement or associated with the voluntary holding of defecation urge which is associated with fecal impaction and constipation.

In a study performed by Schryver et al. ${ }^{23}$, regular sports/physical activity was found to be a protective factor against constipation in adults. This is based on the knowledge that slow gastrointestinal transit time is associated with constipation, and it is assumed that exercise shortens transit time through the gastrointestinal tract. ${ }^{23}$ On the other hand, other authors have put forward no relation between physical exercise and constipation in adults. ${ }^{4}$ Unfortunately, there is limited data in the scientific literature about the effects of physical activity on constipation in children. It was assessed that one of the major contributing factors to childhood constipation with disabilities is physical immobility. ${ }^{24}$ According to our data, constipation was found in $7.23 \%$ of children who had less physical activity and $2.23 \%$ of children who were obese.

\section{Limitations}

This was a single-center study with a small sample size. Information's from caregivers other than parents may not reflect the correct picture.

\section{Conclusion}

Functional constipation was found higher in male, above five-year aged children. Low dietary fiber, consumption of cow's milk, junk food, unwillingness to use toilets in school, busy academic schedules were found to be probably related to functional constipation.

\section{Funding- No fund source.}

\section{Conflict of interest- None.}

\section{References:}

1. Drossman DA. The functional gastrointestinal disorders and the Rome II process. Gut. 1999;45: 2:II1-5. doi: 10.1136/ gut.45.2008.ii1.

2. Kondapalli CS, Gullapalli S. Constipation in children: Incidence, causes in relation to diet pattern and psychological aspects. Int J Contemp Pediatr. 2018 5:613.

3. Hyams JS, Di Lorenzo C, Saps M, Shulman RJ, Staiano A, van Tilburg M. Childhood functional gastrointestinal disorders: child/adolescent. Gastroenterology. 2016 1;150:1456-68.

4. Southwell BR, King SK, Hutson JM. Chronic constipation in children: organic disorders are a major cause. J Paediatr Child Health. 2005;41:1-15.

5. Garrigues V, Galvez C, Ortiz V, Ponce M, Nos P, Ponce J. Prevalence of constipation: agreement among several criteria and evaluation of the diagnostic accuracy of qualifying symptoms and self-reported definition in a population-based survey in Spain. Am J Epidemiol. 2004;159:520-6.

6. Rasquin A, Di Lorenzo C, Forbes D, Guiraldes E, Hyams JS, Staiano A, et al. Childhood functional gastrointestinal disorders: child/adolescent. Gastroenterology. 2006 1;130:1527-37.

7. Hyman PE, Milla P, Beninga MA, Davidso GP, Fleisher DF, Taminiau J. Childhood functional gastrointestinal disorders: Neonate/toddler. Gastroenterology. 2006;130:1519-26.

8. Chan JS. A community-based study of the prevalence of constipation in young children and the role of dietary fibre. Hong Kong Med J. 2005;11: 431-6.

9. Kajiwara M, Inoue K, Usui A, Kurihara M, Usui T. The micturition habits and prevalence of daytime urinary incontinence in Japanese primary school children. J Urol. 2004 ;171:403-7. 
10. Ganinkou RE, Adamidis D, Gianniou M. Epidemiology of chronic constipation in greek children. Hell J Gastroenterol. 1999;12:58-62

11. Khanna V, Poddar U, Yachha SK. Etiology and spectrum of constipation in Indian children. Indian Pediatr. 2010 $1 ; 47: 1025-30$

12. Sonnenberg A, Koch TR. Epidemiology of constipation in the United States. Dis Colon Rectum1989; 32:1-8

13. Bytzer P, Howell S, Leemon M, Young LJ, Jones MP, Talley NJ. Low socioeconomic class is a risk factor for upper and lower gastrointestinal symptoms: a population based study in 15000 Australian adults. Gut. 2001 1;49:66-72.

14. Yousefi A, Mohamadian S, Sharifabadi PM, Nakhaei S, Norouzi E. How Does Functional Constipation Affect Growth Status in Children?. Iran J Pediatr. 2019;29:e85700.

15. Sandler RS, Jordan MC, Shelton BJ. Demographic and dietary determinants of constipation in the US population. Am J Public Health. 1990 ;80:185-9.

16. de Araújo Sant AM, Calçado AC. Constipation in schoolaged children at public schools in Rio de Janeiro, Brazil. J Pediatr Gastroenterol Nutr. 1999;29:190-3.

17. Morais MB, Vitolo MR, Aguirre AN, Fagundes-Neto U. Measurement of low dietary fiber intake as a risk factor for chronic constipation in children. J Pediatr Gastroenterol Nutr. 1999;29:132-5.
18. Loening-Baucke V. Chronic constipation in children. Gastroenterology. 1993;105:1557-64.

19. Andýran F, Dayý S, Mete E. Cows milk consumption in constipation and anal fissure in infants and young children. J Paediatr Child Health. 2003 ;39:329-31.

20. Ozokutan BH, Zoroglu S, Ceylan H, Ozkan KU. Psychological evaluation of children with idiopathic constipation and their parents. Pediatrics international. $2005 ; 47: 311-5$.

21. Lundblad B, Hellström AL. Perceptions of school toilets as a cause for irregular toilet habits among schoolchildren aged 6 to 16 years. J Sch Health. 2005 ;75:125-8.

22. Vernon S, Lundblad B, Hellstrom AL. Children's experiences of school toilets present a risk to their physical and psychological health. Child Care Health Dev. 2003;29:4753.

23. De Schryver AM, Keulemans YC, Peters HP, Akkermans LM, Smout AJ, De Vries WR, Van Berge-Henegouwen GP. Effects of regular physical activity on defecation pattern in middle-aged patients complaining of chronic constipation. Scand J Gastroenterol. 2005 1;40:422-9.

24. Elawad MA, Sullivan PB. Management of constipation in children with disabilities. Dev Med Child Neurol. 2001 1;43:829. 